\title{
Blood pressure levels and cardiovascular risk according to age in patients with diabetes mellitus: a nationwide population-based cohort study
}

Hack-Lyoung Kim ${ }^{1 \dagger}$, Hyue Mee Kim ${ }^{2 \dagger}$, Chang Hee Kwon ${ }^{3}$, Jeong-Hun Shin ${ }^{4}$, Mi-Hyang Jung ${ }^{5}$, Chan Joo Lee ${ }^{6}$, Dae-Hee Kim7, Woo-Hyeun Kim ${ }^{8}$, Si-Hyuck Kang ${ }^{9}$, Ju-Hee Lee ${ }^{10}$, In Jeong Cho ${ }^{11}$, Iksung Cho ${ }^{6}$, Jun Hyeok Lee ${ }^{12}$, Dae Ryong Kang ${ }^{12}$, Hae-Young Lee ${ }^{13}$, Wook-Jin Chung ${ }^{14}$, Sang-Hyun Ihm ${ }^{15}$, Kwang II Kim ${ }^{9}$, Eun Joo Cho ${ }^{16}$, II-Suk Sohn ${ }^{17}$, Hyeon-Chang Kim ${ }^{6}$, Jinho Shinn ${ }^{4}$ Ju Han Kim ${ }^{18}$, Sung Kee Ryu ${ }^{19}$, Seok-Min Kang ${ }^{6}$,

Wook Bum Pyun ${ }^{11}$, Myeong-Chan Cho ${ }^{10}$, Sungha Park ${ }^{6 *}$ and Ki-Chul Sung ${ }^{20^{*}}$ (c)

\begin{abstract}
Background: Little is known about age-specific target blood pressure (BP) in hypertensive patients with diabetes mellitus (DM). The aim of this study was to determine the BP level at the lowest cardiovascular risk of hypertensive patients with DM according to age.
\end{abstract}

Methods: Using the Korean National Health Insurance Service database, we analyzed patients without cardiovascular disease diagnosed with both hypertension and DM from January 2002 to December 2011. Primary end-point was composite cardiovascular events including cardiovascular death, myocardial infarction and stroke.

Results: Of 241,148 study patients, 35,396 had cardiovascular events during a median follow-up period of 10 years. At the age of $<70$ years, the risk of cardiovascular events was lower in patients with $B P<120 / 70 \mathrm{mmHg}$ than in those with BP 130-139/80-89 mmHg. At the age of $\geq 70$, however, there were no significant differences in the risk of cardiovascular events between patients with BP 130-139/80-89 $\mathrm{mmHg}$ and BP $<120 / 70 \mathrm{mmHg}$. The risk of cardiovascular events was similar between patients with BP 130-139/80-89 mmHg and BP 120-129/70-79 mmHg, and it was significantly higher in those with $B P \geq 140 / 90 \mathrm{mmHg}$ than in those with BP $130-139 / 80-89 \mathrm{mmHg}$ at all ages.

Conclusions: In a cohort of hypertensive patients who had DM but no history of cardiovascular disease, lower BP was associated with lower risk of cardiovascular events especially at the age of $<70$. However, low

\footnotetext{
*Correspondence: shpark0530@yuhs.ac; kcmd.sung@samsung.com

${ }^{\dagger}$ Hack-Lyoung Kim and Hyue Mee Kim contributed equally to this manuscript

${ }^{6}$ Division of Cardiology, Severance Cardiovascular Hospital and Cardiovascular Research Institute, Yonsei University College of Medicine, 50-1, Yonsei-ro, Seodaemun-gu, Seoul 03722, Republic of Korea

${ }^{20}$ Division of Cardiology, Department of Internal Medicine, Kangbuk

Samsung Hospital, Sungkyunkwan University School of Medicine, 29 Saemunan-ro, Jongno-gu, Seoul 03181, Republic of Korea

Full list of author information is available at the end of the article
}

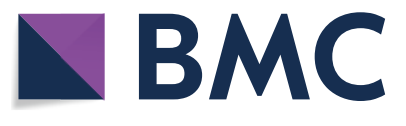

(c) The Author(s) 2020. This article is licensed under a Creative Commons Attribution 4.0 International License, which permits use, sharing, adaptation, distribution and reproduction in any medium or format, as long as you give appropriate credit to the original author(s) and the source, provide a link to the Creative Commons licence, and indicate if changes were made. The images or other third party material in this article are included in the article's Creative Commons licence, unless indicated otherwise in a credit line to the material. If material is not included in the article's Creative Commons licence and your intended use is not permitted by statutory regulation or exceeds the permitted use, you will need to obtain permission directly from the copyright holder. To view a copy of this licence, visit http://creativecommons.org/licenses/by/4.0/. The Creative Commons Public Domain Dedication waiver (http://creativecommons.org/publicdomain/zero/1.0/) applies to the data made available in this article, unless otherwise stated in a credit line to the data. 
$\mathrm{BP}<130-139 / 80-89 \mathrm{mmHg}$ was not associated with decreased cardiovascular risk, it may be better to keep the BP of $130-139 / 80-89 \mathrm{mmHg}$ at the age of $\geq 70$.

Keywords: Age, Cardiovascular risk, Diabetes mellitus, Hypertension, Target blood pressure

\section{Background}

Hypertension and diabetes mellitus (DM), 2 major cardiovascular risk factors, have emerged as major medical and public health issues globally. There has been a continued growth in the prevalence of hypertension [1] and DM [2], and both conditions are associated with increased risk of cardiovascular morbidity and mortality [3-6]. Hypertension affects approximately $70 \%$ of patients with DM, which is twice as common as those without DM [7]. Importantly, the coexistence of hypertension and DM substantially increases in the risk of cardiovascular disease (CVD), and chronic kidney disease $[8,9]$. Two thirds of diabetic patients die from CVD, in which hypertension is the main cause of CVD [10]. Therefore, it is very important to control hypertension in patients with DM in order to reduce their cardiovascular risk and to improve prognosis.

Because blood pressure (BP) rises with age, hypertension is one of the main medical problem with high prevalence in the elderly [11]. Even in elderly people, the beneficial effect of BP control on the reduction in the risk of cardiovascular events has been suggested [12, 13], and BP control should not be neglected. However, elderly subjects are often frail, have many comorbidities, and are more vulnerable to the side effects of intensive BP control [14]. In clinical practice, many physicians are worried about the side effects or complications of intensive BP lowering in elderly patients. Therefore, age must be considered when setting target BP. However, there is limited data regarding age-specific target $\mathrm{BP}$ in patients with DM. The 2017 American College of Cardiology/American Heart Association (ACC/AHA) guidelines suggested a target BP of $130 / 80 \mathrm{mmHg}$ for diabetic patients at all ages [15]. Otherwise, in patients with DM, the European guidelines recommended a target BP of 130/70$79 \mathrm{mmHg}$ and $130-140 / 70-79 \mathrm{mmHg}$ for subjects aged $<65$ years and $\geq 65$ years, respectively [16]. There is still insufficient evidence as to whether BP needs to be lowered intensively in patients with DM and whether the target BP should differ according to age. Thus, the aim of this study was to determine the BP level at the lowest cardiovascular risk of hypertensive patients with DM according to age.

\section{Methods}

Data sources

This study used a database provided by the National Health Insurance Services-Health Screening (NIHSHEALS) cohort in Korea. NHIS is a single insurance provider in Korea and covers $97.2 \%$ of the Korean population; enrollees aged 40 years or older are entitled to a general health screening program every 2 years. A database includes data regarding sociodemographics, use of inpatient and outpatient services, diagnoses, prescriptions, death, and health screening examination data (e.g., health questionnaires and laboratory tests). The cohort details have been previously described [17]. The study was approved by the Institutional Review Board of Kangbuk Samsung Hospital (\# KBSMC 201901-018). The anonymized dataset was provided to the researchers from the NHIS and informed consent was waived.

\section{Study population and patient involvement}

A total of 314,293 subjects who were diagnosed with both hypertension and DM from January 2002 to December 2011 were extracted from the NIHS-HEALS cohort. Subjects were considered as having hypertension if: (1) hypertension was diagnosed before health screening examination, or (2) anti-hypertensive medications were prescribed before. Having DM was defined if: (1) DM was diagnosed before health screening examination, (2) hypoglycemic agents were prescribed before, or (3) fasting glucose $\geq 126 \mathrm{mg} / \mathrm{dL}$. Among them, patients with the following were excluded: prior history of myocardial infarction or stroke $(n=36,712)$, death before second screening $(n=623)$, diagnosis of malignancy $(n=28,410)$, and unavailable data $(\mathrm{n}=7400)$. Therefore, a total of 241,148 patients were finally analyzed. Flow chart for study enrollment is shown in Fig. 1. Individuals were followed up until the development of death, and the first occurrence of cardiovascular events, or the end of the study (December 2017). This research was done without patient involvement.

\section{BP data}

The data on BP records were extracted from the NIHSHEALS cohort. Considering BP variability, $2 \mathrm{BP}$ records within 4 years were averaged. BP measured using a sphygmomanometer or an oscillometric device. BP 
Korean subjects in the National Health Insurance program underwent general health screening and newly diagnosed with both hypertension and diabetes mellitus in 2002-2011 (two or more health screenings were performed within 4 years) $(n=314293)$

Exclusions:

1) Prior history of myocardial infarction or stroke $(n=36712)$

2) Death before second screening $(n=623)$

3) Diagnosis of malignancy $(n=28410)$

4) Unavailable data $(n=7400)$

Final population analyzed in the study $(\mathrm{n}=241148)$

Fig. 1 Study flowchart showing patient enrollment

measurements were recommended twice at 2 min intervals after 5 min of stabilization.

\section{Cardiovascular events}

The collection of information on the occurrence of cardiovascular events began the day after second check-up, and patients with cardiovascular events between 2 checkups were excluded from the study. Baseline clinical data used in this study was obtained from the second checkup. The primary study endpoint was major cardiovascular events including cardiovascular death, myocardial infarction and stroke. A diagnosis of myocardial infarction was made based on discharge diagnosis after a hospitalization (ICD-10 codes: I21-23). A diagnosis of stroke was made based on discharge diagnosis (ICD-10 codes: I60-69) in patients who had been hospitalized and undergone brain imaging [18]. The cause and date of death were confirmed by the records from the National Statistical Office of Korea. The secondary study endpoint was each clinical event.

\section{Statistical analysis}

Continuous variables are expressed as mean (standard deviation) and categorical variables as percentages. The mean values of continuous variables were compared using analysis of variance, and the frequencies of categorical variable were compared using chi-square test among BP category groups. The incidence of endpoints was calculated using the total number of outcomes during the follow-up period divided by 100,000 person-years. Multivariable analysis was performed using the Cox proportional hazard model to evaluate the relationship of BP with the cardiovascular events and mortality. Hazard ration $(\mathrm{HR})$ and 95\% confidence interval $(\mathrm{CI})$ were calculated and adjusted for age, income level, history of smoking, physical activity, alcohol consumption, body mass index, fasting glucose, total cholesterol, and use of aspirin or statin. Subgroup analyses were performed by dividing the patients into those aged $<50$ years, $50-59$ years, 60-69 years, and $\geq 70$ years to determine the appropriate target BP according to age. Restricted cubic splines were fitted to evaluate the non-linear relationship between BP and outcomes. $P$ value $<0.05$ was considered statistically significant. Statistical analyses were performed using SAS Statistical Software (version 9.4, SAS Institute, Cary, North Carolina, USA) and R Statistical Software (version 3.5.2, R Foundation for Statistical Computing, Vienna, Austria).

\section{Results}

\section{Baseline characteristics of the study patients according} to BP categories

The baseline characteristics of the study subjects according to BP categories are shown in Table 1. Compared to the lower BP group, the higher BP group tended to be older and male, had higher BMI, consumed more alcohol, had low household income, had higher level of fasting glucose and total cholesterol, and more frequently used aspirin or antihypertensive medications, and less frequently used statin.

\section{Cardiovascular events according to BP and age categories} A total of 35,396 events occurred during a median followup period of 10.0 years. Cardiovascular events according to BP and age categories are shown in Table 2. In the total population, as BP rose, cardiovascular events more frequently occurred: the incidence of cardiovascular events was lowest in the lowest BP group $(<120 / 70 \mathrm{mmHg})$ 


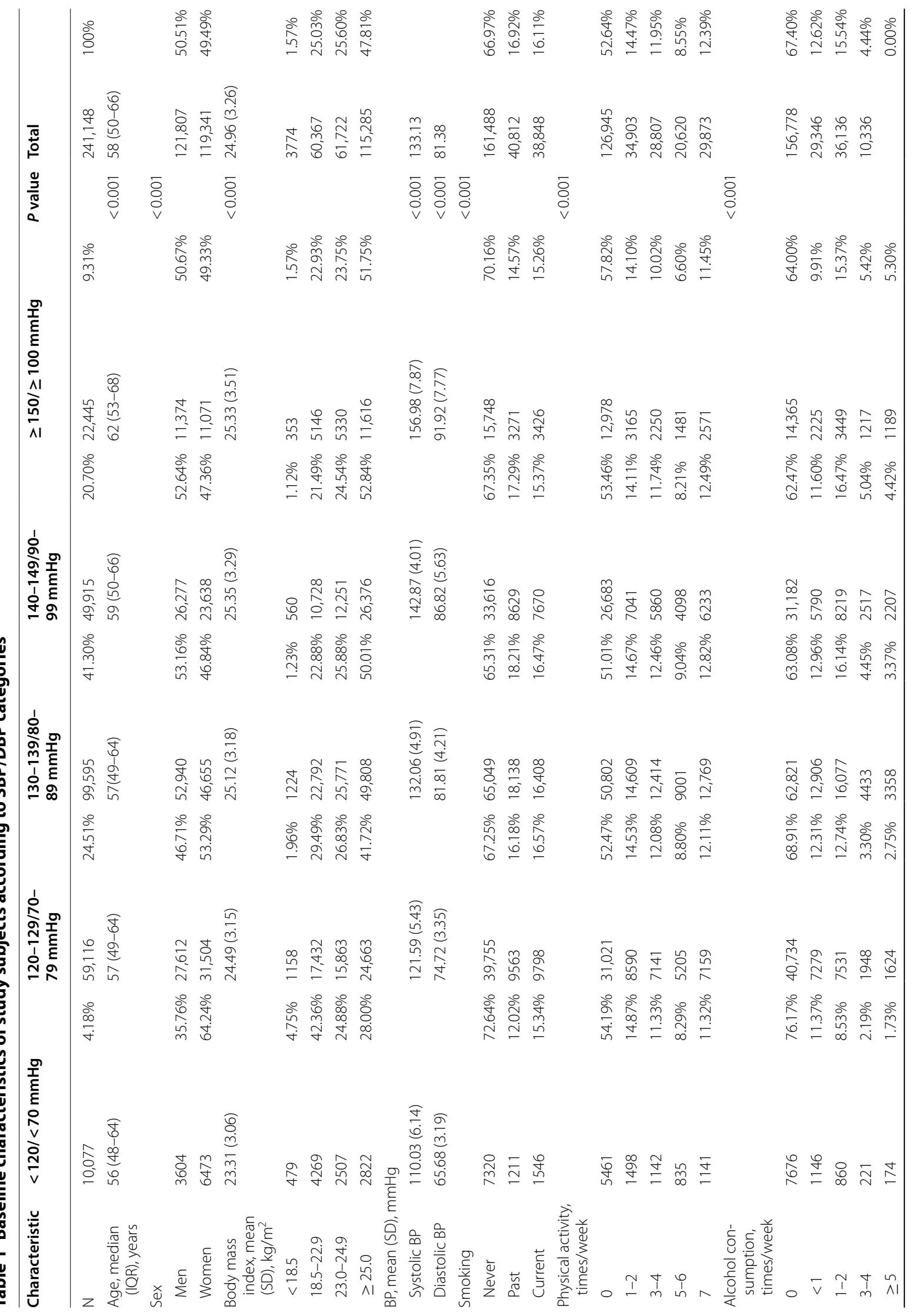




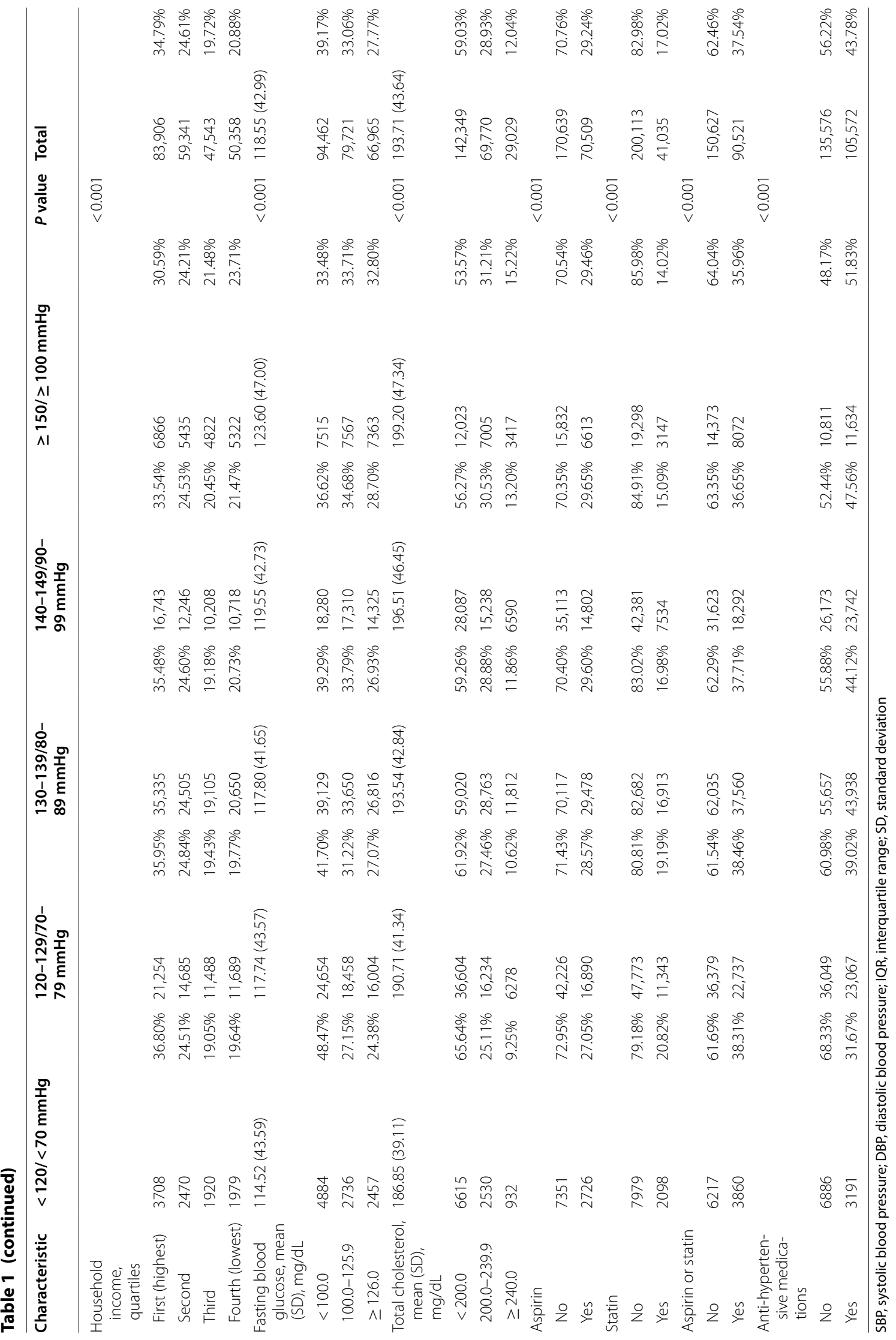


Table 2 Cardiovascular events of study subjects according to BP and age categories

\begin{tabular}{|c|c|c|c|c|c|}
\hline Clinical event & $<120 /<70 \mathrm{mmHg}$ & $120-129 / 70-79 \mathrm{mmHg}$ & $\begin{array}{l}130- \\
139 / 80- \\
89 \mathrm{mmHg}\end{array}$ & $140-149 / 90-99 \mathrm{mmHg}$ & $\geq 150 / \geq 100 \mathrm{mmHg}$ \\
\hline \multicolumn{6}{|l|}{ Total } \\
\hline Events & 1123 & 7625 & 13,764 & 8188 & 4696 \\
\hline Person-years & 92,622 & 567,439 & 983,762 & 484,528 & 204,774 \\
\hline $\begin{array}{l}\text { Incidence (events/100,000 person- } \\
\text { years) }\end{array}$ & 1212 & 1344 & 1399 & 1690 & 2293 \\
\hline Adjusted HR (95\% Cl) & $0.85(0.80-0.90)$ & $0.94(0.92-0.97)$ & Ref & $1.12(1.09-1.15)$ & $1.33(1.29-1.37)$ \\
\hline \multicolumn{6}{|l|}{$<50$ years } \\
\hline Events & 113 & 951 & 1763 & 874 & 430 \\
\hline Person-years & 30,886 & 167,650 & 288,016 & 119,956 & 39,039 \\
\hline $\begin{array}{l}\text { Incidence (events/100,000 person- } \\
\text { years) }\end{array}$ & 366 & 567 & 612 & 729 & 1101 \\
\hline Adjusted HR (95\% Cl) & $0.74(0.61-0.90)$ & $0.96(0.89-1.04)$ & Ref & $1.20(1.10-1.30)$ & $1.79(1.61-1.99)$ \\
\hline \multicolumn{6}{|l|}{$50-59$ years } \\
\hline Events & 265 & 1860 & 3409 & 1815 & 877 \\
\hline Person-years & 27,949 & 182,438 & 318,830 & 146,385 & 55,314 \\
\hline $\begin{array}{l}\text { Incidence (events/100,000 person- } \\
\text { years) }\end{array}$ & 948 & 1020 & 1069 & 1240 & 1585 \\
\hline Adjusted HR (95\% Cl) & $0.87(0.77-0.99)$ & $0.94(0.89-1.00)$ & Ref & $1.16(1.10-1.23)$ & $1.43(1.32-1.54)$ \\
\hline \multicolumn{6}{|l|}{$60-69$ years } \\
\hline Events & 425 & 2999 & 5361 & 3301 & 1916 \\
\hline Person-years & 24,115 & 158,546 & 276,831 & 155,068 & 72,302 \\
\hline $\begin{array}{l}\text { Incidence (events/100,000 person- } \\
\text { years) }\end{array}$ & 1762 & 1892 & 1937 & 2129 & 2650 \\
\hline Adjusted HR (95\% Cl) & $0.86(0.78-0.95)$ & $0.97(0.92-1.01)$ & Ref & $1.09(1.05-1.14)$ & $1.32(1.25-1.39)$ \\
\hline \multicolumn{6}{|l|}{$\geq 70$ years } \\
\hline Events & 320 & 1815 & 3231 & 2198 & 1473 \\
\hline Person-years & 9670 & 58,803 & 100,083 & 63,116 & 38,117 \\
\hline $\begin{array}{l}\text { Incidence (events/100,000 person- } \\
\text { years) }\end{array}$ & 3309 & 3087 & 3228 & 3482 & 3864 \\
\hline Adjusted HR (95\% Cl) & $0.99(0.88-1.11)$ & $0.95(0.89-1.00)$ & Ref & $1.08(1.03-1.14)$ & $1.17(1.10-1.25)$ \\
\hline
\end{tabular}

$\mathrm{HR}$, hazard ratio; $\mathrm{Cl}$, confidence interval. $\mathrm{BP}$, blood pressure

(1212/10,000 person-years), and highest in the highest BP group ( $\geq 150 / 100 \mathrm{mmHg}$ ) (2293/10,000 person-years). Compared to patients with BP 130-139/80-89 mmHg, the risk of cardiovascular events was significantly lower in those with $\mathrm{BP}<120 / 70 \mathrm{mmHg}$ and BP 120-129/70$79 \mathrm{mmHg}$ with HR of 0.85 (95\% CI 0.80-0.90) and HR of 0.94 (95\% CI 0.92-0.97), respectively. Compared to patients with BP 130-139/80-89 mmHg, the risk of cardiovascular events was significantly higher in those with BP 140-149/90-99 $\mathrm{mmHg}$ and $\mathrm{BP} \geq 150 / 100 \mathrm{mmHg}$ with HR of 1.12 (95\% CI 1.09-1.15) and HR of 1.33 (95\% CI 1.29-1.37), respectively.

At the age of $<70$ years, the risk of cardiovascular events was significantly lower in patients with $\mathrm{BP}<120 / 70 \mathrm{mmHg}$ than in those with BP 130139/80-89 mmHg. The risk reduction was stronger at younger ages: HRs (95\% CIs) were 0.74 (0.61-0.90),
0.87 (0.77-0.99), and $0.86(0.78-0.95)$, in patients with $<50$ years, 50-59 years, and 60-69 years, respectively. At the age of $\geq 70$ years, however, there were no significant differences in the risk of cardiovascular events between patients with BP 130-139/80-89 $\mathrm{mmHg}$ and $\mathrm{BP}<120 / 70 \mathrm{mmHg}$ with HR of 0.99 (95\% CI 088-1.11). The risk of cardiovascular events was similar between patients with BP 130-139/80-89 $\mathrm{mmHg}$ and BP 120$129 / 70-79 \mathrm{mmHg}$ at all ages. The risk of cardiovascular events was significantly higher in patients with $\mathrm{BP} \geq 140 / 90 \mathrm{mmHg}$ than those with BP 130-139/80$89 \mathrm{mmHg}$ at all ages. The younger the patients, the higher the risk. Adjusted HRs for the risk of cardiovascular events according to BP and age categories are also demonstrated in Fig. 2. Restricted cubic spline curves show age-specific adjusted hazard ratios for cardiovascular events according to systolic BP (SBP) and diastolic BP 


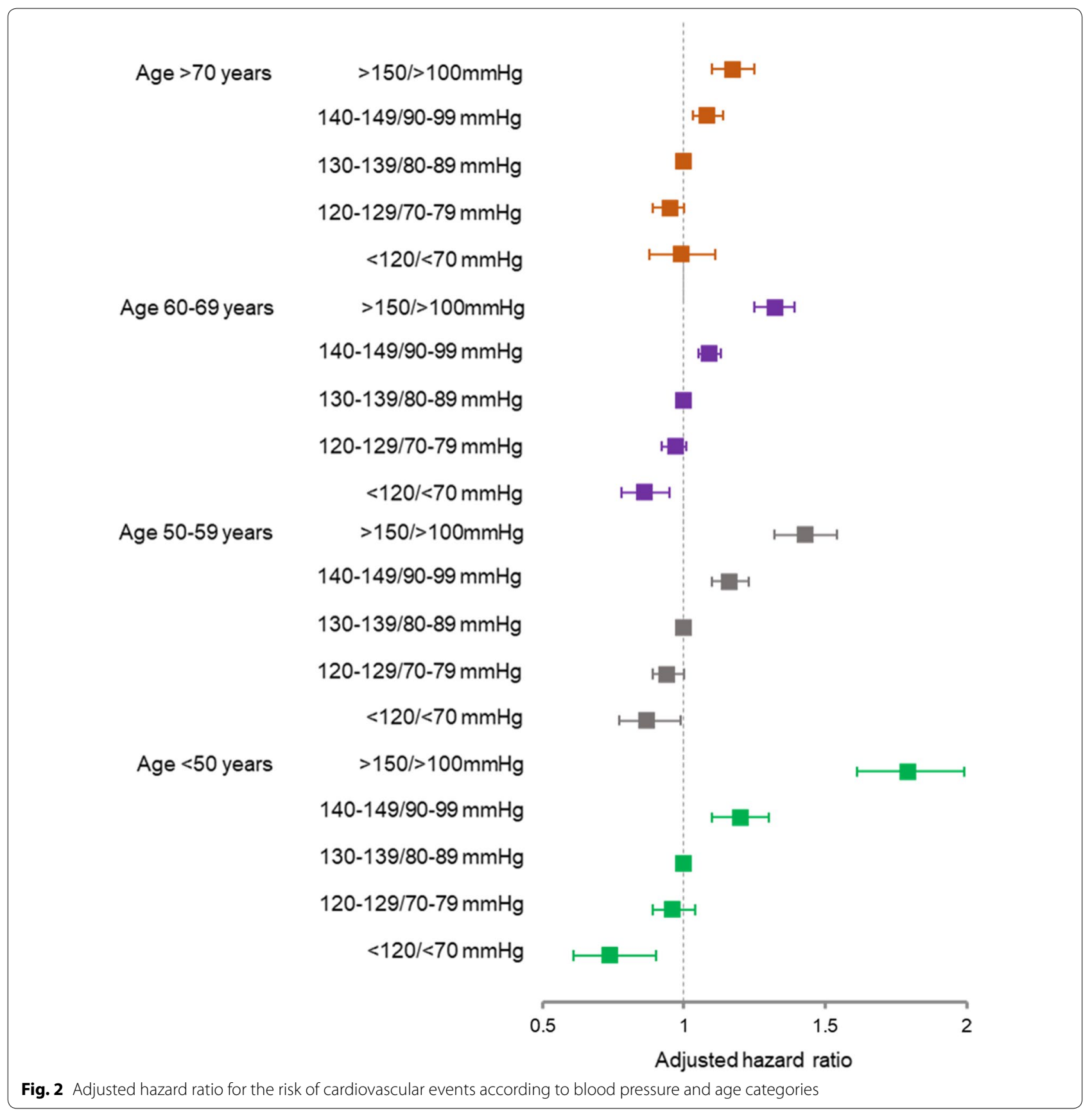

(DBP) categories (Fig. 3). There was a significant interaction between SBP and age for the prediction of cardiovascular events (interaction $P<0.001$ ).

Similar results were obtained in sex-specific analysis (Additional file 1: Tables S1 and S2). Low $\mathrm{BP}<120 / 70 \mathrm{mmHg}$ was more associated with reduced cardiovascular risk in women than in men. The incidence of cardiovascular events with high BP above 130139/80-89 mmHg was consistently observed regardless of obesity (Additional file 1: Tables S3 and S4). All-cause mortality and primary end-point results according to BP and age categories are demonstrated in Additional file 1: Tables S5-S8. The risk of all-cause or cardiovascular mortality was significantly higher in patients with $\mathrm{BP}<120 / 70 \mathrm{mmHg}$ than in those with BP 130-139/80$89 \mathrm{mmHg}$ in patients with age of $\geq 60$ years. The risk of myocardial infarction was not different between patients with $\mathrm{BP}<120 / 70 \mathrm{mmHg}$ and BP 130-139/80-89 mmHg 

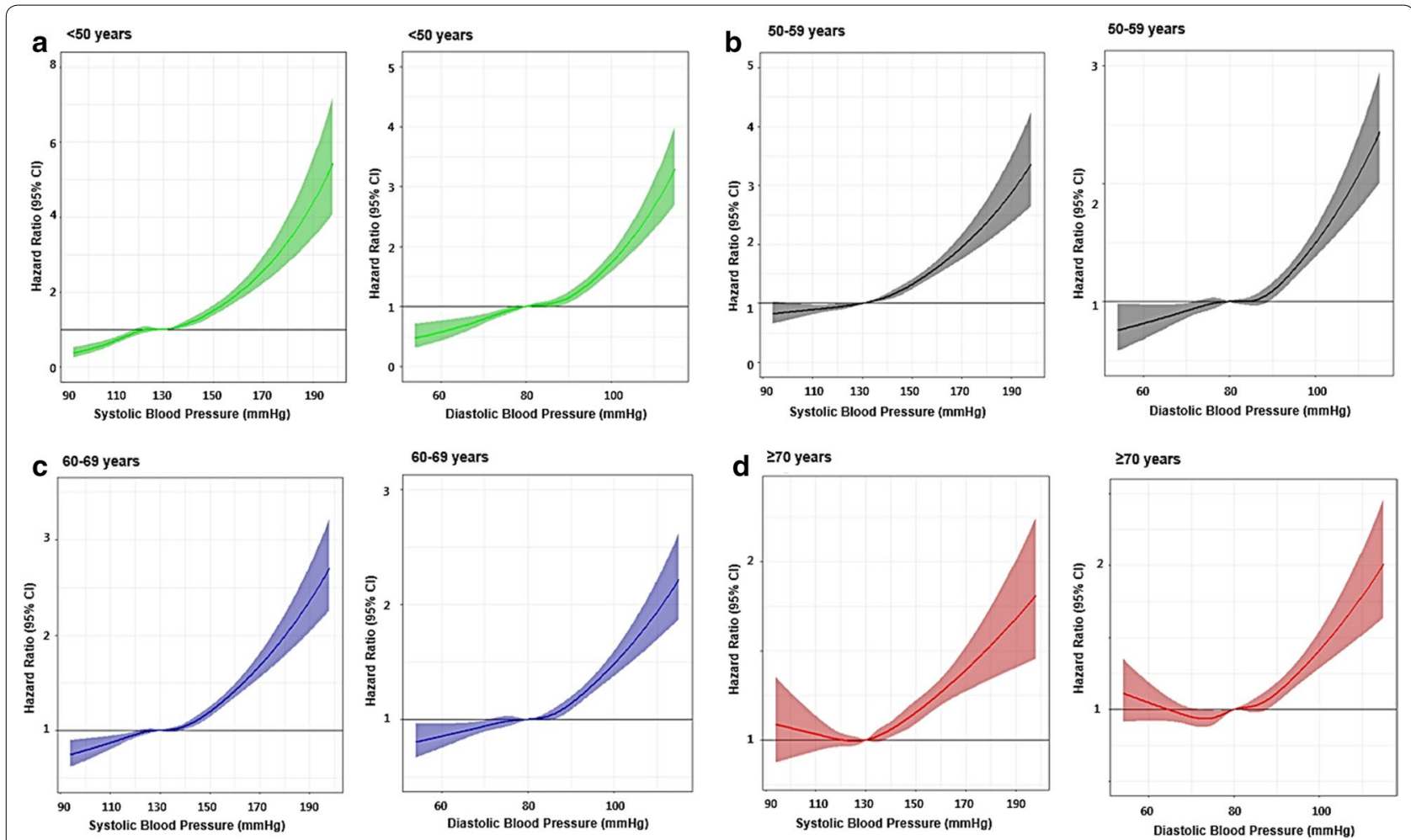

Fig. 3 Restricted cubic spline curves showing age-specific adjusted hazard ratios for the risk of cardiovascular events according to SBP and DBP categories. Solid lines indicate hazard ratios and shaded areas indicate $95 \%$ confidence intervals. SBP, systolic blood pressure; DBP, diastolic blood pressure

at all ages. However, the risk of stroke was significantly lower in patients with $\mathrm{BP}<120 / 70 \mathrm{mmHg}$ than in those with BP 130-139/80-89 $\mathrm{mmHg}$ at all ages. All-cause or cardiovascular mortality and the risk of stroke were significantly higher in patients with $\mathrm{BP}>140 / 90 \mathrm{mmHg}$ than in those with BP 130-139/80-89 mmHg at all ages. The risk of myocardial infarction was significantly increased when $B P$ was $\geq 150 / 90 \mathrm{mmHg}$.

\section{Cardiovascular risks in patients with anti-hypertensive medications}

A total of $105,572(43.8 \%)$ patients were taking antihypertensive medications. In these patients with antihypertensive medications, the risk of cardiovascular events was not different among those with $\mathrm{BP}<120 / 70$, 120-129/70-79, and 130-139/80-89 $\mathrm{mmHg}$, and it was significantly higher in patients with $\mathrm{BP} \geq 140 / 90 \mathrm{mmHg}$ than in those with BP 130-139/80-89 mmHg at the age of $<70$ years. At the age of $\geq 70$ years, the risk of cardiovascular events was not different among patients with $\mathrm{BP}<120 / 70,120-129 / 70-79,130-139 / 80-89$, and 140-149/90-99 $\mathrm{mmHg}$, and it was significantly higher in those with $\mathrm{BP} \geq 150 / 100 \mathrm{mmHg}$ than in those with BP 130-139/80-89 mmHg (Table 3). All-cause and cardiovascular mortality tended to increase in those with $\mathrm{BP}<120 / 70 \mathrm{mmHg}$, compared to those with BP 130 $139 / 80-89 \mathrm{mmHg}$ at all ages (Additional file 1: Tables S9 and S10). At $\mathrm{BP} \geq 150 / 100 \mathrm{mmHg}$, the risk of myocardial infarction tended to increase, but the differences were not statistically significant either age (Additional file 1: Table S11). The lower the blood pressure, the lower the risk of stroke at all ages (Additional file 1: Table S12).

\section{Discussion}

In this nationwide population-based cohort of 241,148 patients with both hypertension and DM, but without CVD, those with $\mathrm{BP}<120 / 70 \mathrm{mmHg}$ had significantly lower risk of cardiovascular events than those with BP $130-139 / 80-89 \mathrm{mmHg}$ at the age of $<70$ years. However, there was no significant difference in the risk of cardiovascular events in patients with $\mathrm{BP}<120 / 70 \mathrm{mmHg}$ and BP $130-139 / 80-89 \mathrm{mmHg}$ at the age $\geq 70$. For patients on anti-hypertensive medications, the risk of cardiovascular events was similar between patients with $\mathrm{BP} \leq 130-139 / 80-89 \mathrm{mmHg}$ and higher in those with $\mathrm{BP} \geq 140 / 90 \mathrm{mmHg}$ at all ages. These results suggest that optimal target BP in patients with DM may differ according to age and that: lowering $\mathrm{BP}$ to $<130 / 80 \mathrm{mmHg}$ may 
Table 3 Cardiovascular events of study subjects with anti-hypertensive medications according to BP and age categories

\begin{tabular}{|c|c|c|c|c|c|}
\hline Clinical event & $<120 /<70 \mathrm{mmHg}$ & $120-129 / 70-79 \mathrm{mmHg}$ & $\begin{array}{l}130- \\
139 / 80- \\
89 \mathrm{mmHg}\end{array}$ & $140-149 / 90-99 \mathrm{mmHg}$ & $\geq 150 / \geq 100 \mathrm{mmHg}$ \\
\hline \multicolumn{6}{|l|}{ Total } \\
\hline Events & 397 & 2901 & 5606 & 3519 & 2145 \\
\hline Person-years & 25,355 & 195,990 & 389,630 & 20,951 & 97,809 \\
\hline $\begin{array}{l}\text { Incidence (events/100,000 person- } \\
\text { years) }\end{array}$ & 1566 & 1480 & 1439 & 16,796 & 2193 \\
\hline Adjusted HR (95\% Cl) & $0.95(0.85-1.05)$ & $0.97(0.93-1.02)$ & Ref & $1.11(1.06-1.16)$ & $1.29(1.23-1.36)$ \\
\hline \multicolumn{6}{|l|}{$<50$ years } \\
\hline Events & 21 & 214 & 511 & 269 & 136 \\
\hline Person-years & 3985 & 35,306 & 80,961 & 38,353 & 13,671 \\
\hline $\begin{array}{l}\text { Incidence (events/100,000 person- } \\
\text { years) }\end{array}$ & 527 & 606 & 631 & 701 & 995 \\
\hline Adjusted HR (95\% Cl) & $0.89(0.57-1.38)$ & $0.97(0.82-1.14)$ & Ref & $1.11(0.95-1.28)$ & $1.58(1.30-1.91)$ \\
\hline \multicolumn{6}{|l|}{$50-59$ years } \\
\hline Events & 78 & 586 & 1285 & 738 & 342 \\
\hline Person-years & 7829 & 63,159 & 127,672 & 62,997 & 25,614 \\
\hline $\begin{array}{l}\text { Incidence (events/100,000 person- } \\
\text { years) }\end{array}$ & 996 & 928 & 1006 & 1171 & 1335 \\
\hline Adjusted HR (95\% Cl) & $0.97(0.77-1.22)$ & $0.91(0.82-1.00)$ & Ref & $1.16(1.06-1.27)$ & $1.28(1.13-1.44)$ \\
\hline \multicolumn{6}{|l|}{ 60-69 years } \\
\hline Events & 151 & 1255 & 2231 & 1450 & 928 \\
\hline Person-years & 8827 & 68,351 & 128,304 & 74,550 & 37,595 \\
\hline $\begin{array}{l}\text { Incidence (events/100,000 person- } \\
\text { years) }\end{array}$ & 1711 & 1836 & 1739 & 1945 & 2468 \\
\hline Adjusted HR (95\% Cl) & $0.95(0.80-1.12)$ & $1.05(0.98-1.13)$ & Ref & $1.10(1.03-1.18)$ & $1.37(1.27-1.48)$ \\
\hline \multicolumn{6}{|l|}{$\geq 70$ years } \\
\hline Events & 147 & 846 & 1579 & 1062 & 739 \\
\hline Person-years & 4713 & 29,172 & 52,691 & 33,611 & 20,927 \\
\hline $\begin{array}{l}\text { Incidence (events/100,000 person- } \\
\text { years) }\end{array}$ & 3119 & 2900 & 2997 & 3160 & 3531 \\
\hline Adjusted HR (95\% Cl) & $1.00(0.85-1.19)$ & $0.95(0.87-1.03)$ & Ref & $1.05(0.97-1.14)$ & $1.15(1.05-1.25)$ \\
\hline
\end{tabular}

$\mathrm{HR}$, hazard ratio; $\mathrm{Cl}$, confidence interval. $\mathrm{BP}$, blood pressure

be effective at the age of $<70$ years, but not in those at the age of $\geq 70$ years. In addition, the lower the better may not be applied in patients on anti-hypertensive medications, because all-cause or cardiovascular mortality tended to be even higher in those with $<120 / 70 \mathrm{mmHg}$. Based on these results, the drug goal should be less than $140 / 90 \mathrm{mmHg}$ but individualized.

Although high prevalence of hypertension in patients with DM [7], and markedly increased risk of cardiovascular events in coexistence of hypertension and DM [8, 9], there is limited data on optimal target BP in patients with DM. In a large randomized controlled trial (RCT) of patients with DM demonstrated that lowering SBP to $<135 \mathrm{mmHg}$ using perindopril and indapamide regimen was shown to be significantly associated with reductions in cardiovascular events, compared to the placebo group whose SBP was maintained at $\sim 140 \mathrm{mmHg}$
[19]. However, another RCT showed that, compared with $135 \mathrm{mmHg}$, an achieved SBP to $121 \mathrm{mmHg}$ did not reduce cardiovascular morbidity and mortality in patients with DM [20]. Meta-analyses confirmed that reduction of SBP of $<140 \mathrm{mmHg}$ is associated with better cardiovascular outcomes [21], but there is no beneficial effect when SBP is lowered to $<130 \mathrm{mmHg}$ in patients with DM [22]. Another meta-analysis of 73,914 subjects with DM reported that lowering SBP to $<130 \mathrm{mmHg}$ recued stroke by $39 \%$; however, there was no risk reduction in myocardial infarction [23]. Excluding the effect of strong glycemic control in diabetic patients, a more intensive lowering SBP to $<130 \mathrm{mmHg}$ improved overall outcomes [24]. On the line of similar results, recent meta-analyses showed that in diabetic patients, if the baseline $\mathrm{SBP} \geq 140 \mathrm{mmHg}$, antihypertensive treatment reduced cardiovascular risk; however, if the baseline 
$\mathrm{SBP}<140 \mathrm{mmHg}$, there was no observed benefit in BP lowering therapy $[25,26]$. As mentioned above, each study has different target BP, and the results are slightly different, making it difficult to clarify where to put the target BP in patients with DM. In a whole study population in our study, the lower the BP, the lower the cardiovascular events, and thus, the target BP of DM may be suggested as $<130 / 80 \mathrm{mmHg}$, if we do not consider age. Most of the existing studies, including meta-analysis, were conducted in the West, but this study is an Asian study, and racial differences should be considered when interpreting our results.

However, age should be considered when setting target $\mathrm{BP}$ in hypertensive subjects. Although lowering BP obviously improves clinical outcome [12,13], adverse effects more frequently occur with intensive treatment in older people $[14,27]$. There is still no standard guideline for target BP in elderly subjects. The 2 most widely used guidelines show somewhat differences in target BP in older people. The 2017 ACC/AHA guideline recommends a target $\mathrm{BP}$ of $<130 / 80 \mathrm{mmHg}$ in the elderly, which is the same in younger age [15]. However, there is disagreement with setting the same target $\mathrm{BP}(<130 / 80 \mathrm{mmHg})$ in subjects aged 30 and 80 years [27]. Indeed, lowering $\mathrm{BP}$ to $<130 / 80 \mathrm{mmHg}$ is difficult in some elderly subjects, especially when they have isolated systolic hypertension and poor vascular compliance [27]. Also, there is concern about more frequent and serious adverse effects from intensive BP control in more frail older subjects [13]. In this context, the 2018 European Society of Cardiology/ European Society of Hypertension (ESC/ESH) guideline recommended that in older subjects on BP-lowering drugs, $\mathrm{BP}$ should be lowered to $<140 / 80 \mathrm{mmHg}$, but not $\mathrm{SBP}<130 \mathrm{mmHg}$ [16]. Although age is an important factor for hypertension control, there have been few studies on whether age should be considered when setting target BP in subjects with DM. In the present study, the risk of cardiovascular events was not different among patients with $\mathrm{BP}<120 / 70,120-129 / 70-79$ and $130-139 / 80-$ $89 \mathrm{mmHg}$ at the age of $\geq 70$ years, suggesting that older subjects with DM do not need strict BP control, which is in line with $2018 \mathrm{ESC} / \mathrm{ESH}$ guideline [16]. For patients on anti-hypertensive medications, our study showed that the risk of cardiovascular events was similar in all patients with $\mathrm{BP} \leq 130-139 / 80-89 \mathrm{mmHg}$ and higher in those with $\mathrm{BP} \geq 140 / 90 \mathrm{mmHg}$, at all ages. Rather, when $\mathrm{BP}$ was lowered to $<130 / 80 \mathrm{mmHg}$, all-cause or cardiovascular mortality tended to rise at all ages. These results suggesting different target BPs according to age and anti-hypertensive medications in diabetic patients deserve attention and could be of clinical use.

The results of the present study showed that the risk of cardiovascular events associated with elevated BP decreased as patients became older: reduction in $\mathrm{BP}$ from $130-139 / 80-89$ to $<120 / 70 \mathrm{mmHg}$ was associated $26 \%$ reduction in the risk of cardiovascular events at the age of $<50$ years, as low as $13 \% \sim 14 \%$ at the age of 50-69 years, and no beneficial effect at the age of $\geq 70$ years. These results are in line with those of previous studies in the general population [28]. In the elderly, irreversible pathological changes in vasculature caused by long-standing high BP may develop and lead to cardiovascular events despite a lowered, even normalized BP [27]. The effective prevention of cardiovascular events can be expected by lowering BP in younger patients with $\mathrm{DM}$, so that they need more strict BP control.

Our results suggest that BP can be safely lowered to $<130 / 80 \mathrm{mmHg}$ in younger patients with $\mathrm{DM}$, but not in elderly diabetics aged $\geq 70$ years. However, current study analyzed diabetic patients who were relatively healthy, had no history of CVD and received regular health check-ups. In high-risk diabetics with a history of CVD, the target BP of $<130 / 80 \mathrm{mmHg}$ may be more appropriate even at the age of $\geq 70$ years $[29,30]$. Otherwise, target BP should not be lowered to $<130 / 80 \mathrm{mmHg}$ in diabetic patients with comorbidities and high frailty even at the age of $<70$ years due to the risk of side effects of intensive BP lowering [31]. Target BP should be individualized according to the risk of cardiovascular events, comorbidities, frailty and age [32]. In addition, the lower the better is not applied in patients on anti-hypertensive medications: at $\mathrm{BP}<140 / 90 \mathrm{mmHg}$, there were no differences in the risk of cardiovascular events, but all-cause and cardiovascular mortality was significantly increased at $\mathrm{BP}<120 / 70 \mathrm{mmHg}$ at all ages. Based on these results, the target goal of anti-hypertensive medications should be $\mathrm{BP}<140 / 90 \mathrm{mmHg}$, but not $\mathrm{BP}<120 / 70 \mathrm{mmHg}$.

\section{Limitations}

Besides inherent shortcomings of the use of administrative database and retrospective design, there are several limitations to this study. First, as the diagnosis of hypertension in our study was based on the diagnostic code, not on the BP levels, there are several possible reasons why many patients diagnosed with hypertension had relatively normal or even low BP, even though many patients were not taking anti-hypertensive medications, as follows: (1) there might be coding errors which have always been an issue when using claim data. Nevertheless, it is reported that the diagnosis accuracy of hypertension is relatively high in claim data (sensitivity $=73 \%$ and positive predictive value $=82 \%$ ) [33], (2) patients who were prescribed anti-hypertensive medications along with health check-ups at regular basis were classified as those who take anti-hypertensive medications in the current study. Thus, it was possible that some 
patients who were prescribed anti-hypertensive medications on an irregular basis or who did not undergo health check-ups would be miss-classified as that they were not taking anti-hypertensive medications even though they were consistently taking the medications, and (3) we used average value of two would be lower than expected. Despite the various shortcomings, claim data has a strength in that it is not limited to a specific doctors or specific medical institutions, and there is no selection bias. In addition, only patients taking antihypertensive medications (they might be certain to be hypertensive) were analyzed separately, and we showed the same results as all patients. Second, as clinic BP measurements were made for the analysis, $\mathrm{BP}$ values might be less accurate. BP values from out-of-office BP monitoring such as ambulatory blood pressure monitoring or home blood pressure monitoring may provide more valuable information [34]. In order to minimize errors and inaccuracies, we averaged 2 measurements of BP. Third, the side effects of lowering BP were not identified in this study. Fourth, as the results of our study were obtained from relatively healthy diabetic patients without CVD, it should be noted that it is difficult to apply our results directly to high-risk patients with CVD or those with comorbidity and high frailty $[29,31]$. Fifth, we need to be careful when interpreting the results for the secondary study endpoint of the study. In the analysis of each clinical event (the secondary study endpoint, represented in Additional file 1), the incidence of clinical event in each group was very low, so the statistical power would have been weakened. Sixth, information on anti-diabetic medications was not available in our study, because some important anti-diabetic drugs such as dipeptidyl peptidase- 4 inhibitors and sodium-glucose co-transporter-2 inhibitors were introduced into the domestic market after patients' enrollment. Lastly, our results were obtained from all Korean patients, so that its application to other ethnic groups may be limited.

\section{Conclusion}

In a cohort of hypertensive patients who had DM but no history of CVD, lower BP was associated with lower risk of cardiovascular events especially at the age of $<70$ years. Effort to lower $\mathrm{BP}$ of $<130 / 80 \mathrm{mmHg}$ may be justified in patients at the age of $<70$ years; however, the intensive BP lowering strategy is less beneficial in those at the age of $\geq 70$ years, and lowering BP to $130-139 / 80-89 \mathrm{mmHg}$ would be appropriate at the age of $\geq 70$. In patients on anti-hypertensive medications, target BP should be $<140 / 90 \mathrm{mmHg}$, but not
$\mathrm{BP}<120 / 70 \mathrm{mmHg}$. Well-designed prospective studies are needed to verify our findings.

\section{Supplementary information}

Supplementary information accompanies this paper at https://doi. org/10.1186/s12933-020-01156-8.

\begin{abstract}
Additional file 1: Table S1. Incidence of primary end-point* according to BP and age categories in men. Table S2. Incidence of primary end-point* according to BP and age categories in women. Table S3. Incidence of primary end-point* according to BP and age categories in patients with body mass index $\geq 25 \mathrm{~kg} / \mathrm{m}^{2}$. Table $\mathbf{S 4}$. Incidence of primary end-point* according to BP and age categories in patients with body mass index < $25 \mathrm{~kg} / \mathrm{m}^{2}$. Table S5. All-cause mortality according BP and age categories. Table S6. Cardiovascular mortality according to BP and age categories. Table S7. Incidence of myocardial infarction according to BP and age categories. Table S8. Incidence of stroke according to BP and age categories. Table S9. All-cause mortality of study subjects with anti-hypertensive medications according to BP and age categories. Table S10. Cardiovascular mortality of study subjects with anti-hypertensive medications according to BP and age categories. Table S11. Incidence of myocardial infarction of study subjects with anti-hypertensive medications according to BP and age categories. Table S12. Incidence of stroke of study subjects with anti-hypertensive medications according to BP and age categories.
\end{abstract}

\section{Abbreviations}

BP: Blood pressure; SBP: Systolic blood pressure; DBP: Diastolic blood pressure; DM: Diabetes mellitus; CVD: Cardiovascular disease; ACC/AHA: American College of Cardiology/American Heart Association; ESC/ESH: European Society of Cardiology/European Society of Hypertension; NIHS-HEALS: National Health Insurance Services-Health Screening; RCT: Randomized controlled trial.

\section{Acknowledgements}

This study was supported by the Korean Society of Hypertension. The National Health Information Database was provided by the NHIS of Korea (NHIS-2019-1-216).

\section{Authors' contributions}

$\mathrm{H}$-LK and HMK researched data and wrote the manuscript. CHK, JHL and DRK provided essential materials and performed analysis. CHK, JHS, M-HJ, CJL, D-HK, WK, S-HK, J-HL, IJC, IC, H-YL, W-JC, S-HL, KIK, EJC, I-SS, H-CK, JS, JHK, SKR, S-MK, WBP and M-CC read and approved the final manuscript and contributed in revising the manuscript critically for important intellectual content. SP and K-CS revised the manuscript and had primary responsibility for final content. All authors read and approved the final manuscript.

\section{Funding}

The authors received no specific funding for this work.

\section{Availability of data and materials}

The datasets used and analyzed during the current study are available from the corresponding author on reasonable request.

\section{Ethics approval and consent to participate}

The study design was approved by the local ethics committee (Kangbuk Samsung Hospital) and was conducted according to the Declaration of Helsinki.

\section{Consent for publication \\ The anonymized dataset was provided to the researchers from the NHIS and informed consent was waived.}

\section{Competing interests}

All authors report no conflict of interest.

\section{Author details}

${ }^{1}$ Division of Cardiology, Department of Internal Medicine, Boramae Medical Center, Seoul National University College of Medicine, Seoul, Republic 
of Korea. ${ }^{2}$ Division of Cardiology, Department of Internal Medicine, ChungAng University Hospital, Chung-Ang University, Seoul, Republic of Korea. ${ }^{3}$ Department of Internal Medicine, Konkuk University Medical Center, Konkuk University School of Medicine, Seoul, Republic of Korea. ${ }^{4}$ Division of Cardiology, Department of Internal Medicine, Hanyang University College of Medicine, Seoul, Republic of Korea. ${ }^{5}$ Cardiovascular Center, Dongtan Sacred Heart Hospital, Hallym University College of Medicine, Hwaseong, Republic of Korea. ${ }^{6}$ Division of Cardiology, Severance Cardiovascular Hospital and Cardiovascular Research Institute, Yonsei University College of Medicine, 50-1, Yonsei-ro, Seodaemun-gu, Seoul 03722, Republic of Korea. ${ }^{7}$ Division of Cardiology, Asan Medical Center, University of Ulsan College of Medicine, Seoul, Republic of Korea. ${ }^{8}$ Cardiovascular Center, Korea University Guro Hospital, Seoul, Republic of Korea. ${ }^{9}$ Department of Internal Medicine, Seoul National University Bundang Hospital, Seoul National University College of Medicine, Seongnam, Republic of Korea. ${ }^{10}$ Division of Cardiology, Department of Internal Medicine, Chungbuk National University Hospital, Chungbuk National University College of Medicine, Cheongju, Republic of Korea. ${ }^{11}$ Division of Cardiology, Department of Internal Medicine, Ewha Womans University Medical Center, Seoul, Republic of Korea. ${ }^{12}$ Center of Biomedical Data Science, Wonju College of Medicine, Yonsei University, Wonju, Republic of Korea. ${ }^{13}$ Division of Cardiology, Department of Internal Medicine, Seoul National University Hospital, Seoul, Republic of Korea. ${ }^{14}$ Division of Cardiology, Department of Internal Medicine, Gil Hospital, Gachon University, Incheon, Republic of Korea. ${ }^{15}$ Division of Cardiology, Department of Internal Medicine, Bucheon St. Mary's Hospital, The Catholic University of Korea, Bucheon, Republic of Korea. ${ }^{16}$ Division of Cardiology, Department of Internal Medicine, Yeouido St. Mary's Hospital, The Catholic University of Korea, Seoul, Republic of Korea. ${ }^{17}$ Division of Cardiology, Department of Internal Medicine, KyungHee University at Gangdong, Seoul, Republic of Korea. ${ }^{18}$ Division of Cardiology, Department of Internal Medicine, Chonnam National University Hospital, Gwangju, Republic of Korea. ${ }^{19}$ Division of Cardiology, Department of Internal Medicine, Eulji Medical School of Medicine, Seoul, Republic of Korea. ${ }^{20}$ Division of Cardiology, Department of Internal Medicine, Kangbuk Samsung Hospital, Sungkyunkwan University School of Medicine, 29 Saemunan-ro, Jongno-gu, Seoul 03181, Republic of Korea.

Received: 13 July 2020 Accepted: 10 October 2020

Published online: 19 October 2020

\section{References}

1. Worldwide trends in blood pressure from 1975 to 2015 : a pooled analysis of 1479 population-based measurement studies with 19.1 million participants. Lancet. 2017;389:37-55.

2. Global, regional, and national incidence, prevalence, and years lived with disability for 310 diseases and injuries, 1990-2015: a systematic analysis for the Global Burden of Disease Study 2015. Lancet. 2016;388:1545-1602.

3. Lawes CM, Vander Hoorn S, Rodgers A. Global burden of blood-pressurerelated disease, 2001. Lancet. 2008;371:1513-8.

4. Flint AC, Conell C, Ren X, et al. Effect of systolic and diastolic blood pressure on cardiovascular outcomes. N Engl J Med. 2019;381:243-51.

5. Laing SP, Swerdlow AJ, Slater SD, et al. Mortality from heart disease in a cohort of 23,000 patients with insulin-treated diabetes. Diabetologia. 2003:46:760-5.

6. Orasanu G, Plutzky J. The pathologic continuum of diabetic vascular disease. J Am Coll Cardiol. 2009;53:S35-42

7. Klein $R$, Klein BE, Lee KE, et al. The incidence of hypertension in insulindependent diabetes. Arch Intern Med. 1996;156:622-7.

8. Adler Al, Stratton IM, Neil HA, et al. Association of systolic blood pressure with macrovascular and microvascular complications of type 2 diabetes (UKPDS 36): prospective observational study. BMJ. 2000;321:412-9.

9. Wannamethee SG, Shaper AG, Lennon L, et al. Metabolic syndrome vs Framingham Risk Score for prediction of coronary heart disease, stroke, and type 2 diabetes mellitus. Arch Intern Med. 2005;165:2644-50.

10. Sowers JR, Epstein M, Frohlich ED. Diabetes, hypertension, and cardiovascular disease: an update. Hypertension. 2001;37:1053-9.

11. Kearney PM, Whelton M, Reynolds K, et al. Global burden of hypertension: analysis of worldwide data. Lancet. 2005;365:217-23.

12. Beckett NS, Peters R, Fletcher AE, et al. Treatment of hypertension in patients 80 years of age or older. N Engl J Med. 2008;358:1887-98.
13. Williamson JD, Supiano MA, Applegate WB, et al. Intensive vs standard blood pressure control and cardiovascular disease outcomes in adults aged z75 years: a randomized clinical trial. JAMA. 2016;315:2673-82.

14. Benetos A, Petrovic M, Strandberg T. Hypertension management in older and frail older patients. Circ Res. 2019;124:1045-60.

15. Whelton PK, Carey RM, Aronow WS, et al. 2017 ACC/AHA/AAPA/ABC/ACPM/ AGS/APhA/ASH/ASPC/NMA/PCNA Guideline for the prevention, detection, evaluation, and management of high blood pressure in adults: a report of the American College of Cardiology/American Heart Association Task Force on clinical practice guidelines. Hypertension. 2018;71:e13-115.

16. Williams B, Mancia G, Spiering W, et al. 2018 ESC/ESH Guidelines for the management of arterial hypertension. Eur Heart J. 2018;39:3021-104.

17. Seong SC, Kim YY, Park SK, et al. Cohort profile: the National Health Insurance Service- National Health Screening Cohort (NHIS-HEALS) in Korea. BMJ Open. 2017;7:e016640.

18. Park TH, Choi JC. Validation of stroke and thrombolytic therapy in Korean National Health Insurance claim data. J Clin Neurol. 2016;12:42-8.

19. Patel A, MacMahon S, Chalmers J, et al. Effects of a fixed combination of perindopril and indapamide on macrovascular and microvascular outcomes in patients with type 2 diabetes mellitus (the ADVANCE trial): a randomised controlled trial. Lancet. 2007;370:829-40.

20. Cushman WC, Evans GW, Byington RP, et al. Effects of intensive blood-pressure control in type 2 diabetes mellitus. N Engl J Med. 2010;362:1575-85.

21. Bangalore S, Kumar S, Lobach I, et al. Blood pressure targets in subjects with type 2 diabetes mellitus/impaired fasting glucose: observations from traditional and bayesian random-effects meta-analyses of randomized trials. Circulation. 2011;123:2799-810.

22. Thomopoulos C, Parati G, Zanchetti A. Effects of blood-pressure-lowering treatment on outcome incidence in hypertension: 10-should blood pressure management differ in hypertensive patients with and without diabetes mellitus? Overview and meta-analyses of randomized trials. J Hypertens. 2017;35:922-44

23. Reboldi G, Gentile G, Angeli F, et al. Effects of intensive blood pressure reduction on myocardial infarction and stroke in diabetes: a meta-analysis in 73,913 patients. J Hypertens. 2011;29:1253-69.

24. Margolis KL, O'Connor PJ, Morgan TM, et al. Outcomes of combined cardiovascular risk factor management strategies in type 2 diabetes: the ACCORD randomized trial. Diabetes Care. 2014;37:1721-8.

25. Brunstrom M, Carlberg BO. Effect of antihypertensive treatment at different blood pressure levels in patients with diabetes mellitus: systematic review and meta-analyses. BMJ. 2016;352:717.

26. Edmin CA, Rahimi K, Neal B, et al. Blood pressure lowering in type 2 diabetes: a systemic review and meta-analysis. JAMA. 2015;313:603-15.

27. Messerli FH, Bangalore S, Messerli AW. Age, blood pressure targets, and guidelines: rift between those who preach, those who teach, and those who treat? Circulation. 2018;138:128-30.

28. Lewington S, Clarke R, Qizilbash N, et al. Age-specific relevance of usual blood pressure to vascular mortality: a meta-analysis of individual data for one million adults in 61 prospective studies. Lancet. 2002;360:1903-13.

29. Cardiovascular disease and risk management. standards of medical care in diabetes-2019. Diabetes Care. 2019;42:S103-23.

30. Shen $Y$, Dai $Y$, Wang $X Q$, et al. Searching for optimal blood pressure targets in type 2 diabetic patients with coronary artery disease. Cardiovasc Diabetol. 2019;18:160.

31. Solini A, Grossman E. What should be the target blood pressure in elderly patients with diabetes? Diabetes Care. 2016;39(Suppl 2):S234-43.

32. Sternlicht $H$, Basile J. Hypertension in the elderly: recent developments and insights. Curr Opin Cardiol. 2020;35:351-6.

33. Quan H, Khan N, Hemmelgarn BR, et al. Validation of a case definition to define hypertension using administrative data. Hypertension. 2009;54:1423-8.

34. Dolan E, Stanton A, Thijis L, et al. Superiority of ambulatory over clinic blood pressure measurement in predicting mortality: the Dublin outcome study. Hypertension. 2005;46:156-61.

\section{Publisher's Note}

Springer Nature remains neutral with regard to jurisdictional claims in published maps and institutional affiliations. 